\title{
Host-microbe interactions in distal airways: relevance to chronic airway diseases
}

\author{
Clémence Martin ${ }^{1}$, Pierre-Régis Burgel ${ }^{1}$, Patricia Lepage ${ }^{2}$, Claire Andréjak $^{3}$, \\ Jacques de Blic ${ }^{4}$, Arnaud Bourdin ${ }^{5}$, Jacques Brouard ${ }^{6}$, Pascal Chanez ${ }^{7}$, \\ Jean-Charles Dalphin ${ }^{8}$, Gaetan Deslée ${ }^{9}$, Antoine Deschildre ${ }^{10}$, \\ Philippe Gosset ${ }^{11,12}$, Lhousseine Touqui ${ }^{13}$ and Daniel Dusser ${ }^{1}$
}

\begin{abstract}
Affiliations: ${ }^{1}$ Hôpital Cochin, AP-HP, Université Paris Descartes, Sorbonne Paris Cité, Paris, France. ${ }^{2}$ UMR1913-Microbiologie de l'Alimentation au Service de la Santé, l'Institut National de la Recherche Agronomique, Jouy-en-Josas, France. ${ }^{3}$ Respiratory Intensive Care Unit, Centre Hospitalier Universitaire Sud, Amiens, France. ${ }^{4}$ Hôpital Necker-Enfants Malades, AP-HP, Université Paris Descartes, Paris, France. ${ }^{5}$ Hôpital Arnaud de Villeneuve, CHU Montpellier, Montpellier, France. ${ }^{6}$ Dept of Pediatrics, CHU de Caen, Research Unit EA 4655 U2RM, Caen, France. ${ }^{7}$ Dépt des Maladies Respiratoires, AP-HM, Laboratoire d'immunologie INSERM CNRS U 1067, UMR 7733, Aix Marseille Université, Marseille, France. ${ }^{8}$ Hôpital Jean Minjoz, Besançon, France. ${ }^{9}$ Dept of Pulmonary Medicine, University Hospital of Reims, Reims, France. ${ }^{10}$ Hôpital Jeanne de Flandres, CHRU de Lille, Lille, France. ${ }^{11}$ Unité de défense innée et inflammation, Institut Pasteur, Paris, France. ${ }^{12}$ INSERM U874, Paris, France. ${ }^{13}$ Institut Pasteur de Lille, Centre d'Infection et d'Immunité de Lille, Lille, France.
\end{abstract}

Correspondence: Pierre-Régis Burgel, Service de Pneumologie, Hôpital Cochin, 27 rue du Faubourg St Jacques, 75679 Paris Cedex 14, France. E-mail: pierre-regis.burgeldacch.aphp.fr

ABSTRACT This article is the summary of a workshop, which took place in November 2013, on the roles of microorganisms in chronic respiratory diseases. Until recently, it was assumed that lower airways were sterile in healthy individuals. However, it has long been acknowledged that microorganisms could be identified in distal airway secretions from patients with various respiratory diseases, including cystic fibrosis $(\mathrm{CF})$ and non-CF bronchiectasis, chronic obstructive pulmonary disease, asthma and other chronic airway diseases (e.g. post-transplantation bronchiolitis obliterans). These microorganisms were sometimes considered as infectious agents that triggered host immune responses and contributed to disease onset and/or progression; alternatively, microorganisms were often considered as colonisers, which were considered unlikely to play roles in disease pathophysiology. These concepts were developed at a time when the identification of microorganisms relied on culture-based methods. Importantly, the majority of microorganisms cannot be cultured using conventional methods, and the use of novel culture-independent methods that rely on the identification of microorganism genomes has revealed that healthy distal airways display a complex flora called the airway microbiota. The present article reviews some aspects of current literature on host-microbe (mostly bacteria and viruses) interactions in healthy and diseased airways, with a special focus on distal airways.

@ERSpublications

Understanding host-microbe interactions in distal airways may lead to novel therapies for chronic airway diseases http://ow.ly/HfENz

\section{Introduction}

This review is the summary of the fourth of a series of workshops exploring the roles of distal airways in chronic airway diseases, including asthma [1], chronic obstructive pulmonary disease (COPD) [2] and other

Received: Nov 242014 | Accepted: Dec 132014

Conflict of interest: Disclosures can be found alongside the online version of this article at err.ersjournals.com

Provenance: Publication of this peer-reviewed article was supported by Chiesi SA, Courbevoie, France (article sponsor, European Respiratory Review issue 135).

Copyright OERS 2015. ERR articles are open access and distributed under the terms of the Creative Commons Attribution Non-Commercial Licence 4.0. 
respiratory diseases [3]. The focus of this workshop, which took place in Avignon, France, in November 2013, was the roles of microorganisms in chronic respiratory diseases, with a special interest on distal airways.

Inhaled air is contaminated with pollutants, particles and microorganisms (e.g. viruses, bacteria and fungi) that enter the airways during breathing. Until recently, it was assumed that lower airways were sterile in healthy individuals, although it was recognised that upper airways could be colonised by microorganisms. However, it has long been acknowledged that microorganisms could be identified in distal airway secretions from patients with various respiratory diseases, including cystic fibrosis $(\mathrm{CF})$ and non-CF bronchiectasis, COPD, asthma and other chronic airway diseases (e.g. post-transplantation bronchiolitis obliterans). These microorganisms were sometimes considered as infectious agents that triggered host immune responses and contributed to disease onset and/or progression; alternatively, microorganisms were often considered as colonisers, which were considered unlikely to play roles in disease pathophysiology. Importantly, these concepts were developed at a time when the identification of microorganisms exclusively relied on culture-based methods. It is now clear that the majority of microorganisms cannot be cultured using conventional methods, and the use of novel culture-independent methods that rely on the identification of microorganism genomes has revealed that healthy distal airways display a complex flora called the airway microbiota. Recent studies have focused on changes in the airway microbiota under various pathophysiological conditions. The objective of the present article was to review some aspects of current literature on host-microbe (mostly bacteria and viruses) interactions in healthy and diseased airways, with a special focus on distal airways.

\section{Importance of distal airways in chronic airway diseases}

Distal airways, which are usually defined as non-cartilaginous bronchioles with an internal diameter $<2 \mathrm{~mm}$, are considered an important component of chronic airway diseases, including asthma [1], COPD [2], CF [4] and chronic bronchiolitis [3]. Thus, distal airways are the main site of airflow limitation in asthma [5], COPD [6, 7] and post-transplantation bronchiolitis obliterans [8], and these airways appears particularly vulnerable to inhaled pollutants (e.g. cigarette smoke) $[7,9]$.

Although reviewing immune mechanisms in the lung is beyond the scope of this article, there is evidence of innate and adaptive immune mechanisms in distal airways [1-3]. For example, chronic airway diseases are characterised by recruitment of phagocytes (e.g. neutrophils and macrophages) in distal airways and alveoli, and lymphoid follicles have been described in distal airways of COPD patients with severe airflow limitation [10]. These latter structures have been suggested to reflect viral or bacterial infection in distal airways [11]. Importantly, bronchiolar and alveolar epithelium and lung macrophages express pathogen-recognition receptors (e.g. Toll-like receptors) that are necessary to recognise specific pathogen-associated molecular patterns for developing an immune response. Although little data exists on differential response to pathogens in patients with various airway diseases, there is evidence that alveolar macrophages of exacerbation-prone COPD patients are more refractory to cytokine induction by common pathogens (e.g. nontypeable Haemophilus influenza (NTHi), Streptococcus pneumoniae and Moraxella catarrhalis), presumably due to diminished Toll-like receptor-2 and -4 signalling [12]. These data suggest that the immune response to specific microbes could be impaired in disease due to host-specific factors.

\section{From gut to lung microbiome}

The Human Microbiome Project was launched in 2007 to study microbial inhabitants of the human body [13]. At that time, it was realised that human biology may depend, in a large part, on interaction with microbes that live on human mucosal surfaces including skin, mouth and throat, vagina, nostrils and gastrointestinal tracts [13]. Because the human lung was believed to be sterile, it was not included in the original Human Microbiome Project $[14,15]$, although it was later realised that microbial communities also existed in the lung [16]. As a result, knowledge in this field has evolved more rapidly in the gastrointestinal tract than in the lung, and much has to be learnt from studies performed in the gastrointestinal tract.

The human gastrointestinal tract hosts more than 100 trillion bacteria and archaea, which together make up the gut microbiota. The human gut microbiota can be considered an organ within an organ that co-evolved with humans to achieve a symbiotic relationship leading to physiological homeostasis. The human host provides a nutrient-rich environment and the microbiota provides indispensable functions that humans cannot exert themselves. Since most of the bacteria inhabiting the gut are uncultivable, their functions cannot be inferred from composition data. Knowing which microbes are there is not sufficient. Meta-omics has been developed to answer essential questions such as "What is the genetic potential of the non-cultured bacterial fraction of the gut microbiota?" and "What are these microbes really doing?"

Advances in cultivation-independent methods based on analysis of the sequence of the bacterial 16S ribosomal small subunit rRNA gene (which is present in bacterial but not in mammalian genome) quickly expanded our knowledge about the diversity of the microbial ecosystems. First applied to the human gut 
in the late 1990s [17], the actual number of gastrointestinal tract phylotypes (molecular species) detected using molecular techniques has far outnumbered the cultivated gut species. From more than 1200 microbes described, only $12 \%$ were recovered by application of both molecular and cultivation-based approaches, while the vast majority $(\sim 75 \%)$ were only detected through $16 \mathrm{~S}$ rRNA gene sequencing [18]. Chaotic in the early stages of human life [19], the sequential assembly of the human gut microbiota leads to bacterial communities that remain stable over time in healthy conditions in the absence of external perturbations [20]. The average total number of bacterial species was estimated to be close to 1000 per individual, whereas 10000-40000 are predicted for the whole microbiota population [21].

While culture-independent approaches, mainly based on the 16S rRNA gene, provided a better description of the human gut microbiota and the wide diversity of their 100 trillion inhabitants (i.e. the microbiota), recently developed meta-omics allowed the microbiome to be described, originally defined as the totality of microbes, their genetic elements (genomes) and environmental interactions in a defined environment. In this sense, the human microbiome would represent the collection of microorganisms associated with the human body, and their collective genomes would constitute a metagenome. However, the term microbiome is now commonly used to refer to the collective genomes present in members of a given microbiota.

Within the field of meta-omics, metagenomics refers to the genomic analysis applied to all the microorganisms of a microbial ecosystem without previous identification. It encompasses culture-independent studies of the structures and functions of microbial communities and their interactions with the habitats they occupy to understand their biological diversity [22]. Metagenomics provided the evidence that the human gut microbiome contains more than 100 times the number of genes encoded by our own genome [23]. Moreover, human populations can be clustered into three main groups, i.e. enterotypes, based on their microbiome. These enterotypes are characterised by dominant genera and their co-occurring phylogenetic groups that significantly separated the population into three distinct clusters [24].

Remarkably, shifts in the bacterial make-up of the human gut microbiota have been associated with digestive tract dysfunctions such as inflammatory bowel disease (IBD), irritable bowel syndrome and obesity. 10 years ago, the concept of dysbiosis or unbalanced composition of the intestinal microbiota was introduced in the research field of IBD [25]. Even though a tremendous number of specific bacteria have been shown to be modulated in the IBD microbiota [26], no relevant specific triggering agent has been highlighted, emphasising a clear role of this broad dysbiosis in bacterial communities. A decrease in commensals and symbiotic bacteria belonging to the Firmicutes phylum and associated with an increase in pathobionts (or opportunistic pathogens), mostly from the Proteobacteria phylum, seem to be present in most of these inflammatory conditions. Moreover, a decrease in microbial diversity has repeatedly been described in IBD patients in terms of both bacteria and bacterial genes richness. If this is true for IBD, a similar dysbiosis associated with a drastic loss of diversity may be crucial in other pathologies, such as obesity or metabolic syndrome [27].

The discovery of the lung microbiome has led to a growing number of studies over the past 5 years, and understanding the roles of the lung microbiome in health and disease is now the subject of many studies that have been summarised in recent perspective articles [16, 28, 29]. Although progresses have been made regarding methodological issue (e.g. techniques used for sampling) and descriptions of the main characteristics of the lung microbiome in health and some chronic airway diseases, much is still to be learnt regarding the factors associated with changes in microbial communities and the relevance of these changes to specific host response and disease mechanisms. Figure 1 highlights the possible host-microbe interactions and their relevance to chronic airways disease.

\section{Host-bacteria interactions in chronic airway diseases}

In the next section, we examine the relevance of bacteria to chronic airway disease summarising knowledge obtained using both culture-dependent and culture-independent methods.

\section{Cystic fibrosis}

$\mathrm{CF}$ is a genetic disease characterised by abnormal ion transport, leading to a multi-organ disease predominantly involving the lungs with prominent airway inflammation, leading to bronchiectasis and chronic respiratory failure [30]. Chronic airway infection with specific Gram-negative (e.g. Pseudomonas aeruginosa and/or Burkholderia cepacia) and Gram-positive bacteria (e.g., Staphylococcus aureus) are well-recognised features of CF lung disease [30, 31], explaining the major interest in host-microbe interaction in this disease. At the time of lung transplantation in CF patients, studies of lung explants have revealed that most distal airways show structural abnormalities with mucous plugs [4] containing bacteria macrocolonies [32, 33]. However, in earlier stages of the disease, microbiological data were mostly obtained using bacterial culture of sputum, which are easy to obtain in older children and adult CF patients but do not specifically reflect distal airways. 


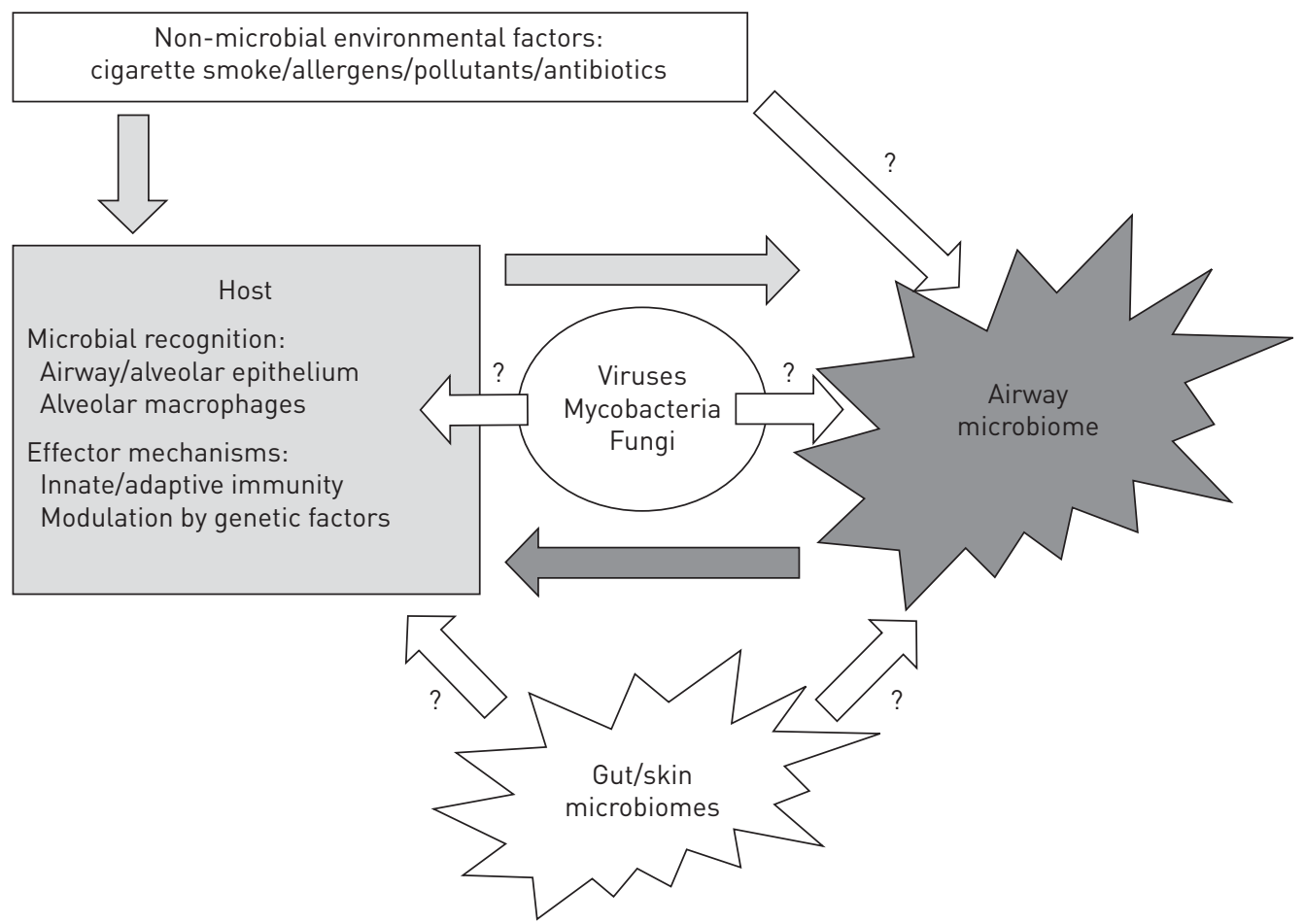

FIGURE 1 Schematic representation of host-microbe interactions in airways. Bacterial airway microbiome is composed of multiple and interacting bacterial communities. Bacteria may interact with other microbes (e.g. mycobacteria, viruses and fungi) and with the host, modulating immune responses. These interactions can be modulated by the effects of environmental factors on the host and/or the microbiome. The role of other bacterial communities, including gut and skin microbiome, in modulating airway diseases is also emerging.

Distal airways in CF neonates, in whom lung structure and function were considered normal at birth, were considered sterile when no pathogen was cultured in upper airway samples [34]. Studies that used cultures of bronchoalveolar lavage (BAL) in young children diagnosed by newborn screening revealed that bacterial infection (e.g. by $S$. aureus, $P$. aeruginosa or $H$. influenzae) in distal airways often occurred early in life in CF children [35-37]. In the AREST-CF (Australian Respiratory Early Surveillance Team for Cystic Fibrosis) study, detection of proinflammatory bacteria (e.g. P. aeruginosa, S. aureus, H. influenzae and S. pneumoniae) in BAL fluid in the first 2 years of life was associated with a clinically significant reduction in lung function measured by forced expiratory volume in $0.75 \mathrm{~s}$ (FEV0.75) [38]. The roles of bacteria cultured in CF airways appear different among different bacteria, although most bacteria cultured in usual aerobic conditions have been associated with significant clinical impact. Chronic airway infection with $P$. aeruginosa and/or B. cepacia [30] is clearly associated with increased airway inflammation, faster lung function decline and poorer prognosis, whereas the impact of other Gram-negative pathogens, including Stenotrophomonas maltophilia [39, 40] or Achromobacter xylosoxidans [41-43], is more controversial. Chronic S. aureus airway infection has been independently associated with haemoptysis in CF patients [44] and recent studies showed that positive sputum cultures for small colony variants (slow-growing antibiotic-resistant mutants) of S. aureus [45] or methicillin-resistant S. aureus [46] were independently associated with disease progression in CF patients. Positive cultures for S. aureus in the BAL fluid of young CF children was associated with a greater rate of decline in lung function [47], further indicating the role of $S$. aureus infection in CF distal airways. Finally, distal airway infection with $P$. aeruginosa, $S$. aureus or other microbes (mixed oral flora and A. fumigatus) was associated with increased IL-8 levels and neutrophil elastase activity in the BAL fluid of young children with CF [48]. Neutrophil elastase activity in BAL fluid is associated with early bronchiectasis in CF children [49].

Because anaerobic conditions exist in mucous plugs in CF airways [32], TunNEY et al. [50] hypothesised that anaerobic bacteria, which are not detected by routine aerobic culture methods, could contribute to the pathophysiology of CF lung disease. These authors found that anaerobic species (Prevotella, Veillonella, Propionibacterium and Actinomyces) were cultured in large numbers from the sputum of adults with $\mathrm{CF}$ and the BAL fluid of children with CF [50]. Colonisation with P. aeruginosa significantly increased the likelihood that anaerobic bacteria would be present in the sputum, thus suggesting interspecies interactions. This latter suggestion was sustained by the fact that all of the anaerobic isolates tested were 
susceptible to meropenem, a common antibiotic used in the treatment of $P$. aeruginosa exacerbation where it shows some superiority over other antipseudomonal antibiotics [50,51]. However, the role of anaerobic bacteria in CF lung disease remains to be established.

Recently, studies have relied on culture-independent methods to examine bacterial contents in CF airways [52]. An important aspect in studies assessing the microbiome in CF patients relates to variability of results in samples obtained in different airway compartments. Sputum may be difficult to obtain in children and paediatric microbiome studies are often based on oral swabs [53, 54]. GoDDARD et al. [55] performed molecular identification of microbiome in oral swabs, sputum and pulmonary explants of CF patients: oral swabs and sputum were discordant in term of diversity and composition, whereas sputum analysis identified prominent lung pathogens found in pulmonary explant analysis. End-stage CF lungs are heterogeneous in terms of tissue damage, suggesting the possibility of topographical variations in microbiota composition. GODDARD et al. [55] analysed lung microbiota in pulmonary explants from different pulmonary lobes, and found an absence of topographical significant change in microbiota composition in 10 patients with end-stage CF lung disease.

The CF microbiome is a complex and dynamic bacterial community [54, 56, 57]. The microbiome is less diverse and much richer in patients with severe CF compared to patients with severe COPD [58]. With the use of culture-independent methods for microbial detection [52, 59], emerging pathogens are becoming of interest. Dynamic microbial composition, richness and diversity in CF airways is now better characterised $[53,54,57,60-63]$. The composition of the CF microbiome can be altered due to clinical (e.g. age and FEV1 decline) and environmental factors (e.g. presence of $P$. aeruginosa, antibiotic exposure, CFTR genotype and gut microbiome) [53, 54, 57, 60-63]. Initially, the airways of children with CF display a rich and diverse microbiome and over time and disease progression the bacterial community decreases in term of diversity, often displaying a predominant pathogen (e.g. P. aeruginosa and/or B. cepacia) $[53,54,57,60]$.

Experimental studies are only beginning to explore the role of microbiome in CF lung disease. A novel CF neonate pig model showed earlier and richer bronchial colonisation and a decrease in bacterial clearance [64, 65], suggesting a predisposition for airway microbiome dysbiosis in CF lungs. Exposure of drosophila to various airway microbiota (obtained from sputum in 44 CF patients) showed three different profiles of fly survival: 1) a synergistic effect of both CF microbiota and $P$. aeruginosa with a diminution of fly survival compared to flies exposed to $P$. aeruginosa alone; 2) no effect of CF microbiota with or without $P$. aeruginosa; and 3) a protective effect of CF microbiota when associated to P. aeruginosa [66]. This study suggests a clear impact of bacterial interactions in microbiota which may exhibit protective or deleterious effects on the host.

The role of antibiotics on airway microbiome is controversial with studies indicating that airway microbiome is highly resilient with a return to basal composition soon after exacerbation and intravenous antibiotics $[60,61]$, whereas other studies describe a significant change in microbiome composition (decreased diversity) linked to antibiotic exposure $[53,67]$. These contradictory findings could be related to a threshold in antibiotic exposure after which the microbiome loses its resilience capacity, a phenomenon which has already been described in the gut microbiome [68]. Overall, antibiotic treatments for recurrent exacerbations have been proven to have a favourable impact on the life expectancy of a CF patient [69]. Nevertheless, understanding the long-term impact of modified microbiome composition due to recurrent antibiotic treatment and/or studying the effect of targeted antibiotic treatments against prominent pathogens as well as non-cultivable bacteria could help in developing novel therapeutic strategies.

\section{Non-CF bronchiectasis}

$P$. aeruginosa and $H$. influenzae are prominent pathogens in patients with non CF-bronchiectasis, and chronic colonisation with $P$. aeruginosa in sputum was associated with poorer prognosis [70]. Recent studies have explored the airway microbiota in patients with non-CF bronchiectasis and a positive correlation between bacterial diversity and FEV1 was reported [71]. RoGERs et al. [72] observed a correlation between microbiota composition and clinical outcome. These authors proposed that patients could be classified into three groups according to the composition of their airway microbiota: 1) P. aeruginosa dominated; 2) H. influenzae dominated; and 3) other taxa dominated. Patients with $P$. aeruginosa- and $H$. influenzae-dominated communities had significantly worse lung function. Predominance of $P$. aeruginosa, followed by Veillonella species, was the best predictor of future exacerbation frequency [72]. Detection of $P$. aeruginosa was associated with poor lung function and exacerbation frequency, irrespective of analytical strategy [72]. The hypothesis that disruption of the lung microbial ecosystem by infection, inflammation and/or antibiotic therapy creates a disturbed, less diversified microbial community with downstream consequences for immune function remains to be further investigated. For example, direct and/or indirect interactions between the predominant species and the wider bacterial community could be implicated in disease outcome [73]. 


\section{COPD}

The role of bacteria in the lower airways of patients with COPD has long been suspected, but has been difficult to establish [74]. To date, most studies have been performed using culture-based techniques with only a few studies being performed using new molecular techniques. Furthermore, many studies relied on sputum examination whereas only a few studies have sampled distal airways using bronchoscopy. SETHI et al. [75] studied BAL in 26 ex-smokers with stable COPD, 20 ex-smokers without COPD and 15 healthy nonsmokers. The authors reported that potentially pathogenic bacteria were cultured $(\geqslant 100$ colony forming units $\mathrm{mL}^{-1}$ ) in approximately one-third of stable COPD patients, whereas potentially pathogenic bacteria were not recovered in ex-smokers without COPD and were cultured in only one of the healthy nonsmokers [75]. Other bronchoscopic studies have also used culture-based techniques and have reported the presence of potentially pathogenic bacteria in the distal airways in $\sim 30 \%$ of stable COPD patients [76-78]. The most frequently isolated potentially pathogenic bacteria was $H$. influenzae, but $S$. pneumonia, M. catarrhalis and $P$. aeruginosa were also found in some COPD patients. One study further described intracellular NTHi in proximal airways of COPD patients by performing in situ hybridisation and immunofluorescence microscopy in bronchial biopsies [78]. An important finding was that colonised COPD (i.e. COPD patients with potentially pathogenic bacteria in distal airways) had greater neutrophil counts and increased concentrations of inflammatory biomarkers (e.g. IL-8 and active matrix metalloproteinase-9) compared with non-colonised COPD patients or ex-smokers and nonsmokers, suggesting that bacterial colonisation could contribute to progression of airway disease in COPD [75]. ZHANG et al. [79] collected sputum samples at baseline and after 1 year in 46 COPD patients and found that $37 \%$ of these patients had bacterial colonisation (defined by $\geqslant 10^{6}$ colony forming units. $\mathrm{mL}^{-1}$ ) at baseline. COPD patients with lower airway bacterial colonisation had increased sputum concentration of IL-8, IL-6 and tumour necrosis factor (TNF)- $\alpha$ compared with COPD patients without colonisation [79]. Interestingly, lower airway bacterial colonisation at baseline was associated with greater decline in lung function and with increased numbers of COPD exacerbations [79]. In a study of 54 COPD patients, PATEL et al. [80] further suggested that the presence of potentially pathogenic bacteria and inflammatory biomarkers (IL-6 and IL-8) in sputum were increased in COPD patients with bronchiectasis and were associated with more frequent and more severe COPD exacerbations.

Another major finding came from molecular characterisation of bacterial strains cultured in sputum of COPD patients. SETH et al. [81] reported that culture of a new strain of H. influenzae, M. catarrhalis or S. pneumonia in sputum was more often associated with the occurrence of COPD exacerbations than when previously isolated strains of these bacteria were cultured. Interestingly, exacerbations associated with new bacterial strains showed increased levels of sputum TNF- $\alpha$ and neutrophil elastase compared with exacerbations associated with pre-existing strains, other pathogens or no pathogens [82].

More recently, studies have focused on describing the airway microbiome in smokers with and without COPD [58, 83-85]. Results of the sequencing in the BAL fluid showed high bacterial diversity; Prevotella, Sphingomonas, Pseudomonas, Acinetobacter, Fusobacterium, Megasphaera, Veillonella, Staphylococcus and Streptococcus constituted the major part of the core microbiome found in healthy subjects and COPD patients [85]. At least two studies suggested that smoking alone did not alter the lung microbiome [83, 84]. One study examined the effect of experimental rhinovirus infection and showed an increase in bacterial burden and a significant outgrowth of $H$. influenzae from the existing microbiota in some, but not all, subjects with COPD [86].

\section{Asthma}

The impact of environmental microbiota on allergic sensitisation leading to asthma onset has been well described [87-91]. Based on data obtained in the PARSIFAL (Prevention of Allergy Risk factors for Sensitization In children related to Farming and Anthroposophic Lifestyle) [92] and GABRIELA [90] cohorts, it is now clear that children who grow up in a rural environment are less likely to develop asthma or any other atopic- or autoimmune-related disease. In a murine model of asthma (ovalbumin sensitisation), mice raised in a sterile environment were more likely to develop airway hyperresponsiveness in comparison to control mice raised in a normal environment [93]. These studies suggest that exposure to a rich and diverse environment microbiota early in life is a strong protective factor against asthma onset.

Airway microbiota has been studied in the BAL fluid of asthmatic children. HiLTY et al. [94] suggested that the distal airway microbiota of asthmatic children contained a higher proportion of Proteobacteria (e.g. Haemophilus, Neisseria, etc.) and Staphylococcus whereas Bacteroidetes were increased in healthy children. HuANG et al. [95] demonstrated that bronchial epithelial brushings of adult asthmatic patients presented a richer and less diverse microbiota than control subjects; bronchial hyperresponsiveness was negatively correlated to microbiome diversity. In contrast with these data, MARRI et al. [96] reported a lower diversity in the induced sputum of nonasthmatic subjects and that Proteobacteria were present in higher proportions 
in the sputum of asthmatic patients, whereas Firmicutes and Actinobacteria were more frequently found in nonasthmatic subjects.

The possible impact of bacterial colonisation on asthma onset and asthma exacerbations has been the focus of many studies. Studies have investigated bacterial colonisation in patients with preschool asthma [97-100] and reported colonisation prevalence ranging from $12.5 \%$ to $61 \%$, with the large variations being ascribed to differences in patient characteristics, sampling and threshold in bacterial culture positivity. Bacterial colonisation was also reported in the sputum of older children and adult patients during exacerbations or under basal conditions [101, 102]. In the Copenhagen Prospective Study on Asthma in Childhood (COPSAC) cohort [103], asthma, prevalence of wheezing, exacerbation severity, eosinophil blood count and total serum IgE were measured at 4 years of age. 1-month-old children were cultured for the presence of $H$. influenzae, M. catarrhalis and/or S. pneumoniae in hypopharyngeal aspiration and $21 \%$ had colonisation with one or a combination of these organisms [103]. No correlation was found with S. aureus colonisation (61\% of patients) in older patients ( 1 year-old). When analysing immune response profiles in the COPSAC cohort, T-helper cell (Th)1/Th2/Th17 profiles were associated with $H$. influenzae and M. catarrhalis colonisation for 1 month, whereas colonisation with $S$. aureus was associated with Th17 profile, suggesting a bacterial colonisation-specific immunomodulation with unknown consequences [104]. Only one retrospective study on the effect of antibiotic treatment in asthma exacerbation of preschool children showed an improvement in severe asthma control in children receiving antibiotic treatment [100]. These findings suggest that, along with the fact that high environmental microbiota diversity is associated with a decrease in the risk of developing asthma, colonisation with selected prominent bronchial bacteria is correlated with a higher risk of asthma. In a recent study, Goleva et al. [105] studied the effect of airway microbiota composition on corticosteroid response in asthmatic subjects. Corticosteroid-resistant asthmatic patients demonstrated airway expansion of specific Gram-negative bacteria, which induced corticosteroid resistance through transforming growth factor- $\beta$ activated kinase- $1 /$ mitogen-activated protein kinase activation [105], highlighting possible effects of the airway microbiome on response to therapy.

\section{Post-transplantation bronchiolitis obliterans}

The outcome of lung transplantation is mainly impaired by infections and the development of bronchiolitis obliterans syndrome (BOS), also called chronic allograft dysfunction [106]. De novo airway colonisation with $P$. aeruginosa in transplanted patients is an independent risk factor for BOS development $[107,108]$. Studies using culture-independent methods have revealed that lung transplant patients have a specific lung microbiome which differs from pre-transplant lung microbiome and changes over time [109]. Willner et al. [110] found that recolonisation of the allograft by $P$. aeruginosa in individuals with CF is not associated with BOS (in contrast to findings with de novo colonisation) and that re-establishment of pretransplant lung populations in the allograft seems to have a protective effect against BOS. These intriguing and novel findings suggest important roles for bacterial microbiome in the development of BOS involving host-bacterial interactions.

\section{Non-tuberculous mycobacteria}

Airway infection with non-tuberculous mycobacteria (NTM) can develop in patients without previous immunodepression status and/or pulmonary disease. KuBo et al. [111] compared lung function and high-resolution computed tomography (CT) scans in 12 women diagnosed with Mycobacterium avium pulmonary infection versus nine healthy controls. Whereas no difference was observed in FEV1, M. avium-infected patients demonstrated a significant decrease in forced expiratory flow at $25-50 \%$ of forced vital capacity and showed significant increases in residual volume (\% predicted) and residual volume/total lung capacity (\%), indicating lung hyperinflation. Analysis of inspiratory and expiratory CT scans revealed that gas trapping was increased in patients with M. avium pulmonary infection [111].

NTM may also occur in patients with previous airway disease, including COPD, asthma or CF. In a casecontrol study comparing 332 patients with pulmonary NTM infection versus 3320 controls [112]. COPD (OR 15.7, 95\% CI 11.4-21.5) was described as a risk factor for NTM pulmonary infection; the association was even stronger in COPD patients who received previous or ongoing inhaled corticosteroid treatment (OR 19.6, 95\% CI 9.7-39.6) [112]. NTM pulmonary infection was further identified as a risk factor for lung function decline in COPD patients [113]. ANDRÉJAK et al. [112] also identified asthma as an independent risk factor for NTM pulmonary infection (OR 7.8, 95\% CI 5.2-11.6), and inhaled corticosteroids have also been associated with NTM infection in asthmatic patients [114]. CF appears to be an independent risk factor for NTM pulmonary infection [112]. EsTHER et al. [115] followed 1216 CF patients for 8 years, 536 had positive sputum cultures for Mycobacterium abscessus (55.6\%) and M. avium (35.4\%). M. abscessus infection was an independent risk factor for FEV1 decline. Olivier et al. [116] followed 159 patients for 15 months; 60 patients had positive sputum culture for NTM (75\% M. avium). 
No difference was found in FEV1 decline but CT scan impairments and progression were increased in the NTM infected group.

Hypersensitivity pneumonitis is one of the most frequent causes of small airways diseases and is usually due to the inhalation of organic dust (e.g. mouldy hay or straw) or chemical compounds (e.g. isocyanates) [3]. Hypersensitivity pneumonitis also occurred after exposure to M. avium in hot tubs (hot tub lung) $[117,118]$ or to Mycobacterium immunogenum in metal working fluids used in the industrial sector (machine operator's lung) [119]. In both cases of NTM-induced hypersensitivity pneumonitis, patients have no history of previous pulmonary disease. Treatment was based on exposure avoidance without any NTM-specific therapy.

\section{Viruses}

\section{Cystic fibrosis}

Respiratory viruses are commonly found in CF airways. A recent prospective study among 100 adult $\mathrm{CF}$ patients followed up for 12 months, in whom sputum, nose and throat swabs were collected every 2 months and at onset of pulmonary exacerbation, concluded that respiratory viruses were detected at $30.5 \%$ of visits and human rhinovirus accounted for $72.5 \%$ of viruses [120]. These findings confirm the prevalence of rhinovirus found in previous studies in CF children [121-123]. The effects of seasonal changes on CF exacerbation occurrence remain unclear [124], but viral infections can trigger pulmonary exacerbations in adult and paediatric CF patients. RAMIREZ et al. [125] studied the antiviral response gene expression in CF patients with positive viral PCR in sputum and concluded that virus-induced exacerbations were associated with virus-specific immune responses. The relationship between viral infection and disease progression has been described in several studies [126-128], suggesting a possible role for viral infection on bacterial colonisation. JOHANSEN et al. [129] described a seasonal distribution of $P$. aeruginosa chronic infection onset with a peak in incidence in November in Danish CF children. In addition, studies have shown that acquisition of $P$. aeruginosa in CF patients is often preceded by a viral respiratory infection [126, 130]. VAN EWIK et al. [131] studied the possible interactions between $P$. aeruginosa and rhinovirus in vitro and found that respiratory syncytial virus (RSV) infection of cultured epithelial cells enhanced pseudomonal cell adherence as RSV possibly acts as a coupling between $P$. aeruginosa and epithelial cells. These data suggest a role of specific viral-bacterial interactions in exacerbations of CF lung disease.

\section{Asthma}

Understanding the relationship between childhood-onset asthma and viral bronchiolitis is an important aim. In mice, viral infection promotes a Th2 inflammation and proallergic response to allergen exposure [132]. Parinfluenzae type 1 virus induced persistent distal airway lesions (at 3 and 14 months after inoculation) in rodents, which correlated to functional abnormalities [133]. These experimental data suggest that bronchiolitis could be the first step in childhood-onset asthma. Nevertheless, an observational study of a monozygotic twin cohort with discordant history of bronchiolitis showed no difference in terms of frequency of asthma, sensitisation or respiratory function [134].

Wheezing episodes early in life are mostly consequences of viral infection [135], especially with RSV (children aged $<1$ year) or huamn rhinovirus (hRV). RSV-related bronchiolitis in children aged $<1$ year justifies hospital intake in $<5 \%$ of cases. hRV infection frequency increases with age [136], and hRV A and $\mathrm{C}$ are associated with severe respiratory exacerbations $[137,138]$. RSV involvement in the origin of asthma has been the focus of several investigations. Presentation of RSV-associated bronchiolitis (severity, recurrence of wheezing and asthma) differs depending on studied populations [139]. RSV bronchiolitis is considered a risk factor for developing asthma in childhood [140, 141], and only one study has described no increase in asthma frequency in 13-year-old children after RSV infection in early life [142]. BACHARIER et al. [141] described other factors associated with asthma onset after RSV infection including maternal asthma, airway allergen sensitisation at 3 years of age, recurrent episodes of wheezing before the age of 3 years, and exposure to canine allergens. In the same study, the authors suggested that overexpression of CCL5 in nasal epithelium cells during bronchiolitis episodes could be another predictive factor for asthma during childhood [141]. Finally, in a population of 260000 children, JAMES et al. [143] estimated that $13 \%$ of asthma cases were direct consequences of a previous episode of RSV bronchiolitis. RSV-related bronchiolitis is a risk factor for asthma onset in childhood depending on the severity of the episode and frequency is higher in susceptible populations.

$\mathrm{hRV}$ infection is involved in recurrent episodes of childhood wheezing and asthma onset; this implication is even more frequent in the case of associated risk factors not linked to the severity of hRV-related bronchiolitis [144-147]. In the Childhood Origins of ASThma (COAST) cohort, which studied 285 neonates with at least one atopic and/or asthmatic parent, the prevalence of wheezing episodes during the first 6 years 
of life in relation to history of RSV- and hRV-related bronchiolitis was studied [136, 148]. hRV-related bronchiolitis was identified as a risk factor for onset of wheezing episodes at 3 years of age (OR 10, 95\% CI 4.1-26), and this association was maintained at 6 years of age (OR 9.8, 95\% CI 4.3-22). Unlike other viruses, hRV-related bronchiolitis seems to be related to a decline in respiratory function [149].

Genetic background involvement in asthma onset after viral infection has been described previously by CARROLl et al. [139], who showed that maternal asthma was a risk factor for childhood onset asthma after hRV bronchiolitis. CALISKAN et al. [150] described that variants at the 17q21 locus were associated with asthma in children who had hRV wheezing illnesses with expression of two genes at this locus (OR 26.1, 95\% CI 5.1-133.0). The risk of developing asthma was significantly higher in comparison to neonates with only hRV infection or with only the variant genotype [150]. In addition, IL-10 polymorphisms have been described to be associated with hRV bronchiolitis-induced asthma [151], suggesting interactions between viruses and immunity maturation leading to childhood-onset asthma.

Early sensitisation to aero-allergens has been described as being associated with HRV bronchiolitis-induced asthma $[152,153]$. Innate immunity represented by interferon production has been studied in association with childhood wheezing illnesses, early respiratory tract infections, asthma and viral stimulations (mainly hRV) [154-156]. Decrease of interferon-gamma production by mitogen-stimulated mononuclear cells determined from peripheral blood samples in a subset of 9-month-old healthy infants enrolled in the Tucson Children's Respiratory Study was associated with a significantly higher risk of wheezing between 2 and 13 years of age (relative risk 2.29, 95\% CI 1.35-3.89) [154]. The association between impaired basal respiratory function (before any wheezing exacerbation) and the risk of bronchiolitis has been studied previously and the results showed that early obstruction or higher bronchial reactivity was associated with higher risk of hRV-related bronchiolitis [157] or severity of viral exacerbation [158].

\section{Future directions}

Advance in technology, including the discovery of the human airway microbiome, open a new era for the understanding of chronic respiratory diseases. Given the importance of distal airways in chronic airway diseases, it appears essential to understand how changes in composition of the airway microbiome are associated with disease onset, exacerbation and progression. Current challenges are related to sampling of the distal airway microbiome without contamination of the oropharyngeal microbiome and/or proximal airway microbiome. To date, most studies have been performed in relatively small numbers of patients and have mostly described the microbial communities in proximal and distal airways, but the role of the airway microbiome in disease is far from understood. Human data will be usefully complemented by experimental models, including animal studies. The role of specific microbes in modulating the effects of other microbes in disease is starting to emerge: for example, $P$. aeruginosa has been suggested to contribute to $S$. aureus eradication in CF airways by stimulating synthesis secretory phospholipase A2-IIA (a host enzyme with bactericidal activity) [159]. Furthermore, most studies have focussed on a single group of microbes (e.g. bacteria), whereas interactions between various infectious agents (e.g. viruses and bacteria [86] or fungi [160]) are probably important in chronic respiratory diseases. Mycobacteria have also been suggested to act on the immune system with potential therapeutic use in asthmatic patients [161]. Furthermore, the role of the microbial community outside of the lung (e.g. gut and skin microbiome) in modulating airway disease is emerging $[88,89]$. These discoveries have the potential to change the understanding of host-microbe interactions and their relevance in respiratory disease, which may lead to novel therapeutic approaches of chronic airway disease.

\section{References}

1 Burgel PR, de Blic J, Chanez P, et al. Update on the roles of distal airways in asthma. Eur Respir Rev 2009; 18 : $80-95$.

2 Burgel PR, Bourdin A, Chanez P, et al. Update on the roles of distal airways in COPD. Eur Respir Rev 2011; 20: $7-22$.

3 Burgel PR, Bergeron A, de Blic J, et al. Small airways diseases, excluding asthma and COPD: an overview. Eur Respir Rev 2013; 22: 131-147.

4 Burgel PR, Montani D, Danel C, et al. A morphometric study of mucins and small airway plugging in cystic fibrosis. Thorax 2007; 62: 153-161.

5 Yanai M, Sekizawa K, Ohrui T, et al. Site of airway obstruction in pulmonary disease: direct measurement of intrabronchial pressure. J Appl Physiol (1985) 1992; 72: 1016-1023.

6 Hogg JC, Macklem PT, Thurlbeck WM. Site and nature of airway obstruction in chronic obstructive lung disease. N Engl J Med 1968; 278: 1355-1360.

7 McDonough JE, Yuan R, Suzuki M, et al. Small-airway obstruction and emphysema in chronic obstructive pulmonary disease. N Engl J Med 2011; 365: 1567-1575.

8 Verleden SE, Vasilescu DM, Willems S, et al. The site and nature of airway obstruction after lung transplantation. Am J Respir Crit Care Med 2014; 189: 292-300.

9 Mitzner W. Emphysema - a disease of small airways or lung parenchyma? N Engl J Med 2011; 365: 1637-1639. 
10 Hogg JC, Chu F, Utokaparch S, et al. The nature of small-airway obstruction in chronic obstructive pulmonary disease. N Engl J Med 2004; 350: 2645-2653.

11 Sethi S. Chronic obstructive pulmonary disease and infection. Disruption of the microbiome? Ann Am Thorac Soc 2014; 11; Suppl. 1, S43-S47.

12 Berenson CS, Kruzel RL, Eberhardt E, et al. Impaired innate immune alveolar macrophage response and the predilection for COPD exacerbations. Thorax 2014; 69: 811-818.

13 Relman DA. Microbiology: learning about who we are. Nature 2012; 486: 194-195.

14 Human Microbiome Project Consortium. Structure, function and diversity of the healthy human microbiome. Nature 2012; 486: 207-214.

15 Human Microbiome Project Consortium. A framework for human microbiome research. Nature 2012; 486 215-221.

16 Huang YJ, Charlson ES, Collman RG, et al. The role of the lung microbiome in health and disease. A National Heart, Lung, and Blood Institute workshop report. Am J Respir Crit Care Med 2013; 187: 1382-1387.

17 Suau A, Bonnet R, Sutren M, et al. Direct analysis of genes encoding 16S rRNA from complex communities reveals many novel molecular species within the human gut. Appl Environ Microbiol 1999; 65: 4799-4807.

18 Zoetendal EG, Rajilic-Stojanovic M, de Vos WM. High-throughput diversity and functionality analysis of the gastrointestinal tract microbiota. Gut 2008; 57: 1605-1615.

19 Mackie RI, Sghir A, Gaskins HR. Developmental microbial ecology of the neonatal gastrointestinal tract. Am J Clin Nutr 1999; 69: 1035S-1045S.

20 De La Cochetiere MF, Durand T, Lepage P, et al. Resilience of the dominant human fecal microbiota upon short-course antibiotic challenge. J Clin Microbiol 2005; 43: 5588-5592.

21 Tap J, Mondot S, Levenez F, et al. Towards the human intestinal microbiota phylogenetic core. Environ Microbiol 2009; 11: 2574-2584.

22 Rondon MR, Raffel SJ, Goodman RM, et al. Toward functional genomics in bacteria: analysis of gene expression in Escherichia coli from a bacterial artificial chromosome library of Bacillus cereus. Proc Natl Acad Sci USA 1999; 96: 6451-6455.

23 Qin J, Li R, Raes J, et al. A human gut microbial gene catalogue established by metagenomic sequencing. Nature 2010; 464: 59-65.

24 Arumugam M, Raes J, Pelletier E, et al. Enterotypes of the human gut microbiome. Nature 2011; 473: 174-180

25 Tamboli CP, Neut C, Desreumaux P, et al. Dysbiosis as a prerequisite for IBD. Gut 2004; 53: 1057.

26 Nagalingam NA, Lynch SV. Role of the microbiota in inflammatory bowel diseases. Inflamm Bowel Dis 2012; 18: 968-984.

27 Cotillard A, Kennedy SP, Kong LC, et al. Dietary intervention impact on gut microbial gene richness. Nature 2013; 500: 585-588

28 Han MK, Huang YJ, Lipuma JJ, et al. Significance of the microbiome in obstructive lung disease. Thorax 2012; 67: 456-463.

29 Dickson RP, Martinez FJ, Huffnagle GB. The role of the microbiome in exacerbations of chronic lung diseases. Lancet 2014; 384: 691-702.

30 O'Sullivan BP, Freedman SD. Cystic fibrosis. Lancet 2009; 373: 1891-1904.

31 UK Cystic Fibrosis Registry. Annual Data Report 2012. www.cysticfibrosis.org.uk/media/316760/Scientific\% 20Registry\%20Review\%202012.pdf Date last updated: September 2013. Date last accessed: January 22, 2015.

32 Worlitzsch D, Tarran R, Ulrich M, et al. Effects of reduced mucus oxygen concentration in airway Pseudomonas infections of cystic fibrosis patients. J Clin Invest 2002; 109: 317-325.

33 Ulrich M, Herbert S, Berger J, et al. Localization of Staphylococcus aureus in infected airways of patients with cystic fibrosis and in a cell culture model of S. aureus adherence. Am J Respir Cell Mol Biol 1998; 19: 83-91.

34 Linnane BM, Hall GL, Nolan G, et al. Lung function in infants with cystic fibrosis diagnosed by newborn screening. Am J Respir Crit Care Med 2008; 178: 1238-1244.

35 Armstrong DS, Grimwood K, Carlin JB, et al. Bronchoalveolar lavage or oropharyngeal cultures to identify lower respiratory pathogens in infants with cystic fibrosis. Pediatr Pulmonol 1996; 21: 267-275.

36 Sly PD, Brennan S, Gangell C, et al. Lung disease at diagnosis in infants with cystic fibrosis detected by newborn screening. Am J Respir Crit Care Med 2009; 180: 146-152.

37 Armstrong DS, Grimwood K, Carlin JB, et al. Lower airway inflammation in infants and young children with cystic fibrosis. Am J Respir Crit Care Med 1997; 156: 1197-1204.

38 Ramsey KA, Ranganathan S, Park J, et al. Early respiratory infection is associated with reduced spirometry in children with cystic fibrosis. Am J Respir Crit Care Med 2014; 190: 1111-1116.

39 Goss CH, Mayer-Hamblett N, Aitken ML, et al. Association between Stenotrophomonas maltophilia and lung function in cystic fibrosis. Thorax 2004; 59: 955-959.

40 Dalboge CS, Hansen CR, Pressler T, et al. Chronic pulmonary infection with Stenotrophomonas maltophilia and lung function in patients with cystic fibrosis. J Cyst Fibros 2011; 10: 318-325.

41 Ronne Hansen C, Pressler T, Hoiby N, et al. Chronic infection with Achromobacter xylosoxidans in cystic fibrosis patients; a retrospective case control study. J Cyst Fibros 2006; 5: 245-251.

42 De Baets F, Schelstraete P, Van Daele S, et al. Achromobacter xylosoxidans in cystic fibrosis: prevalence and clinical relevance. J Cyst Fibros 2007; 6: 75-78.

43 Hansen CR, Pressler T, Nielsen KG, et al. Inflammation in Achromobacter xylosoxidans infected cystic fibrosis patients. J Cyst Fibros 2010; 9: 51-58.

44 Flume PA, Yankaskas JR, Ebeling M, et al. Massive hemoptysis in cystic fibrosis. Chest 2005; 128: 729-738.

45 Wolter DJ, Emerson JC, McNamara S, et al. Staphylococcus aureus small-colony variants are independently associated with worse lung disease in children with cystic fibrosis. Clin Infect Dis 2013; 57: 384-391.

46 Dasenbrook EC, Checkley W, Merlo CA, et al. Association between respiratory tract methicillin-resistant Staphylococcus aureus and survival in cystic fibrosis. JAMA 2010; 303: 2386-2392.

47 Pillarisetti N, Williamson E, Linnane B, et al. Infection, inflammation, and lung function decline in infants with cystic fibrosis. Am J Respir Crit Care Med 2011; 184: 75-81.

48 Gangell C, Gard S, Douglas T, et al. Inflammatory responses to individual microorganisms in the lungs of children with cystic fibrosis. Clin Infect Dis 2011; 53: 425-432. 
Sly PD, Gangell CL, Chen L, et al. Risk factors for bronchiectasis in children with cystic fibrosis. N Engl J Med 2013; 368: 1963-1970.

Tunney MM, Field TR, Moriarty TF, et al. Detection of anaerobic bacteria in high numbers in sputum from patients with cystic fibrosis. Am J Respir Crit Care Med 2008; 177: 995-1001.

Blumer JL, Saiman L, Konstan MW, et al. The efficacy and safety of meropenem and tobramycin vs ceftazidime and tobramycin in the treatment of acute pulmonary exacerbations in patients with cystic fibrosis. Chest 2005; 128: 2336-2346.

Bittar F, Rolain JM. Detection and accurate identification of new or emerging bacteria in cystic fibrosis patients. Clin Microbiol Infect 2010; 16: 809-820.

Klepac-Ceraj V, Lemon KP, Martin TR, et al. Relationship between cystic fibrosis respiratory tract bacterial communities and age, genotype, antibiotics and Pseudomonas aeruginosa. Environ Microbiol 2010; 12: $1293-1303$. Cox MJ, Allgaier M, Taylor B, et al. Airway microbiota and pathogen abundance in age-stratified cystic fibrosis patients. PLoS One 2010; 5: e11044.

Goddard AF, Staudinger BJ, Dowd SE, et al. Direct sampling of cystic fibrosis lungs indicates that DNA-based analyses of upper-airway specimens can misrepresent lung microbiota. Proc Natl Acad Sci USA 2012; 109: 13769-13774.

van der Gast CJ, Walker AW, Stressmann FA, et al. Partitioning core and satellite taxa from within cystic fibrosis lung bacterial communities. ISME J 2011; 5: 780-791.

Guss AM, Roeselers G, Newton IL, et al. Phylogenetic and metabolic diversity of bacteria associated with cystic fibrosis. ISME J 2011; 5: 20-29.

Sze MA, Dimitriu PA, Hayashi S, et al. The lung tissue microbiome in chronic obstructive pulmonary disease. Am J Respir Crit Care Med 2012; 185: 1073-1080.

Bittar F, Richet H, Dubus JC, et al. Molecular detection of multiple emerging pathogens in sputa from cystic fibrosis patients. PLoS One 2008; 3: e2908.

Fodor AA, Klem ER, Gilpin DF, et al. The adult cystic fibrosis airway microbiota is stable over time and infection type, and highly resilient to antibiotic treatment of exacerbations. PLoS One 2012; 7: e45001.

Stressmann FA, Rogers GB, van der Gast CJ, et al. Long-term cultivation-independent microbial diversity analysis demonstrates that bacterial communities infecting the adult cystic fibrosis lung show stability and resilience. Thorax 2012; 67: 867-873.

Filkins LM, Hampton TH, Gifford AH, et al. Prevalence of streptococci and increased polymicrobial diversity associated with cystic fibrosis patient stability. J Bacteriol 2012; 194: 4709-4717.

Zhao J, Schloss PD, Kalikin LM, et al. Decade-long bacterial community dynamics in cystic fibrosis airways. Proc Natl Acad Sci USA 2012; 109: 5809-5814.

Stoltz DA, Meyerholz DK, Pezzulo AA, et al. Cystic fibrosis pigs develop lung disease and exhibit defective bacterial eradication at birth. Sci Transl Med 2010; 2: 29ra31.

Pezzulo AA, Tang XX, Hoegger MJ, et al. Reduced airway surface $\mathrm{pH}$ impairs bacterial killing in the porcine cystic fibrosis lung. Nature 2012; 487: 109-113.

Sibley CD, Duan K, Fischer C, et al. Discerning the complexity of community interactions using a Drosophila model of polymicrobial infections. PLoS Pathog 2008; 4: e1000184.

Zhao J, Murray S, Lipuma JJ. Modeling the impact of antibiotic exposure on human microbiota. Sci Rep 2014; 4: 4345 .

Dethlefsen L, Relman DA. Incomplete recovery and individualized responses of the human distal gut microbiota to repeated antibiotic perturbation. Proc Natl Acad Sci USA 2011; 108: Suppl. 1, 4554-4561.

2012; 186: 593-597.

Martinez-Garcia MA, de Gracia J, Vendrell Relat M, et al. Multidimensional approach to non-cystic fibrosis bronchiectasis: the FACED score. Eur Respir J 2014; 43: 1357-1367.

Rogers GB, van der Gast CJ, Cuthbertson L, et al. Clinical measures of disease in adult non-CF bronchiectasis correlate with airway microbiota composition. Thorax 2013; 68: 731-737.

Rogers GB, Zain NM, Bruce KD, et al. A novel microbiota stratification system predicts future exacerbations in bronchiectasis. Ann Am Thorac Soc 2014; 11: 496-503.

Rogers GB, van der Gast CJ, Serisier DJ. Predominant pathogen competition and core microbiota divergence in chronic airway infection. ISME J 2015; 9: 217-225.

Sethi S, Murphy TF. Infection in the pathogenesis and course of chronic obstructive pulmonary disease. $N$ Engl $J$ Med 2008; 359: 2355-2365.

Sethi S, Maloney J, Grove L, et al. Airway inflammation and bronchial bacterial colonization in chronic obstructive pulmonary disease. Am J Respir Crit Care Med 2006; 173: 991-998.

Weinreich UM, Korsgaard J. Bacterial colonisation of lower airways in health and chronic lung disease. Clin Respir J 2008; 2: 116-122.

Rosell A, Monso E, Soler N, et al. Microbiologic determinants of exacerbation in chronic obstructive pulmonary disease. Arch Intern Med 2005; 165: 891-897.

Bandi V, Apicella MA, Mason E, et al. Nontypeable Haemophilus influenzae in the lower respiratory tract of patients with chronic bronchitis. Am J Respir Crit Care Med 2001; 164: 2114-2119.

Zhang M, Li Q, Zhang XY, et al. Relevance of lower airway bacterial colonization, airway inflammation, and pulmonary function in the stable stage of chronic obstructive pulmonary disease. Eur J Clin Microbiol Infect Dis 2010; 29: 1487-1493.

Patel IS, Vlahos I, Wilkinson TM, et al. Bronchiectasis, exacerbation indices, and inflammation in chronic obstructive pulmonary disease. Am J Respir Crit Care Med 2004; 170: 400-407.

Sethi S, Evans N, Grant BJ, et al. New strains of bacteria and exacerbations of chronic obstructive pulmonary disease. N Engl J Med 2002; 347: 465-471.

Sethi S, Wrona C, Eschberger K, et al. Inflammatory profile of new bacterial strain exacerbations of chronic obstructive pulmonary disease. Am J Respir Crit Care Med 2008; 177: 491-497.

Erb-Downward JR, Thompson DL, Han MK, et al. Analysis of the lung microbiome in the "healthy" smoker and in COPD. PLoS One 2011; 6: e16384. 
Morris A, Beck JM, Schloss PD, et al. Comparison of the respiratory microbiome in healthy nonsmokers and smokers. Am J Respir Crit Care Med 2013; 187: 1067-1075.

Zakharkina T, Heinzel E, Koczulla RA, et al. Analysis of the airway microbiota of healthy individuals and patients with chronic obstructive pulmonary disease by T-RFLP and clone sequencing. PLoS One 2013; 8: e68302.

Molyneaux PL, Mallia P, Cox MJ, et al. Outgrowth of the bacterial airway microbiome after rhinovirus exacerbation of chronic obstructive pulmonary disease. Am J Respir Crit Care Med 2013; 188: 1224-1231.

Braun-Fahrlander C, Riedler J, Herz U, et al. Environmental exposure to endotoxin and its relation to asthma in school-age children. $N$ Engl J Med 2002; 347: 869-877.

Fyhrquist N, Ruokolainen L, Suomalainen A, et al. Acinetobacter species in the skin microbiota protects against allergic sensitization and inflammation. J Allergy Clin Immunol 2014; 134: 1301-1309.

Trompette A, Gollwitzer ES, Yadava K, et al. Gut microbiota metabolism of dietary fiber influences allergic airway disease and hematopoiesis. Nat Med 2014; 20: 159-166.

Ege MJ, Mayer M, Normand AC, et al. Exposure to environmental microorganisms and childhood asthma. N Engl J Med 2011; 364: 701-709.

Maslowski KM, Mackay CR. Diet, gut microbiota and immune responses. Nat Immunol 2011; 12: 5-9.

Schram-Bijkerk D, Doekes G, Douwes J, et al. Bacterial and fungal agents in house dust and wheeze in children: the PARSIFAL study. Clin Exp Allergy 2005; 35: 1272-1278.

Herbst T, Sichelstiel A, Schar C, et al. Dysregulation of allergic airway inflammation in the absence of microbial colonization. Am J Respir Crit Care Med 2011; 184: 198-205.

Hilty M, Burke C, Pedro H, et al. Disordered microbial communities in asthmatic airways. PLoS One 2010; 5 : e8578.

Huang YJ, Nelson CE, Brodie EL, et al. Airway microbiota and bronchial hyperresponsiveness in patients with suboptimally controlled asthma. J Allergy Clin Immunol 2011; 127: 372-381.

Marri PR, Stern DA, Wright AL, et al. Asthma-associated differences in microbial composition of induced sputum. J Allergy Clin Immunol 2013; 131: 346-352.

Le Bourgeois M, Goncalves M, Le Clainche L, et al. Bronchoalveolar cells in children <3 years old with severe recurrent wheezing. Chest 2002; 122: 791-797.

Saglani S, Nicholson AG, Scallan M, et al. Investigation of young children with severe recurrent wheeze: any clinical benefit? Eur Respir J 2006; 27: 29-35.

Saito J, Harris WT, Gelfond J, et al. Physiologic, bronchoscopic, and bronchoalveolar lavage fluid findings in young children with recurrent wheeze and cough. Pediatr Pulmonol 2006; 41: 709-719.

Schwerk N, Brinkmann F, Soudah B, et al. Wheeze in preschool age is associated with pulmonary bacterial infection and resolves after antibiotic therapy. PLoS One 2011; 6: e27913.

Nagayama Y, Tsubaki T, Nakayama S, et al. Bacterial colonization in respiratory secretions from acute and recurrent wheezing infants and children. Pediatr Allergy Immunol 2007; 18: 110-117.

Zhang Q, Illing R, Hui CK, et al. Bacteria in sputum of stable severe asthma and increased airway wall thickness. Respir Res 2012; 13: 35.

Bisgaard H, Hermansen MN, Buchvald F, et al. Childhood asthma after bacterial colonization of the airway in neonates. N Engl J Med 2007; 357: 1487-1495.

Folsgaard NV, Schjorring S, Chawes BL, et al. Pathogenic bacteria colonizing the airways in asymptomatic neonates stimulates topical inflammatory mediator release. Am J Respir Crit Care Med 2013; 187: 589-595.

Goleva E, Jackson LP, Harris JK, et al. The effects of airway microbiome on corticosteroid responsiveness in asthma. Am J Respir Crit Care Med 2013; 188: 1193-1201.

Yusen RD, Christie JD, Edwards LB, et al. The Registry of the International Society for Heart and Lung Transplantation: Thirtieth Adult Lung and Heart-Lung Transplant Report - 2013; focus theme: age. J Heart Lung Transplant 2013; 32: 965-978.

7 Vos R, Vanaudenaerde BM, Geudens N, et al. Pseudomonal airway colonisation: risk factor for bronchiolitis obliterans syndrome after lung transplantation? Eur Respir J 2008; 31: 1037-1045.

Botha P, Archer L, Anderson RL, et al. Pseudomonas aeruginosa colonization of the allograft after lung transplantation and the risk of bronchiolitis obliterans syndrome. Transplantation 2008; 85: 771-774.

Dickson RP, Erb-Downward JR, Freeman CM, et al. Changes in the lung microbiome following lung transplantation include the emergence of two distinct pseudomonas species with distinct clinical associations. PLoS One 2014; 9: e97214.

Willner DL, Hugenholtz P, Yerkovich ST, et al. Reestablishment of recipient-associated microbiota in the lung allograft is linked to reduced risk of bronchiolitis obliterans syndrome. Am J Respir Crit Care Med 2013; 187: 640-647.

Kubo K, Yamazaki Y, Masubuchi T, et al. Pulmonary infection with Mycobacterium avium-intracellulare leads to air trapping distal to the small airways. Am J Respir Crit Care Med 1998; 158: 979-984. non-tuberculous mycobacteriosis. Thorax 2013; 68: 256-262.

Huang CT, Tsai YJ, Wu HD, et al. Impact of non-tuberculous mycobacteria on pulmonary function decline in chronic obstructive pulmonary disease. Int J Tuberc Lung Dis 2012; 16: 539-545.

Hojo M, Iikura M, Hirano S, et al. Increased risk of nontuberculous mycobacterial infection in asthmatic patients using long-term inhaled corticosteroid therapy. Respirology 2012; 17: 185-190.

Esther CR Jr, Esserman DA, Gilligan P, et al. Chronic Mycobacterium abscessus infection and lung function decline in cystic fibrosis. J Cyst Fibros 2010; 9: 117-123.

Olivier KN, Weber DJ, Lee JH, et al. Nontuberculous mycobacteria. II: nested-cohort study of impact on cystic fibrosis lung disease. Am J Respir Crit Care Med 2003; 167: 835-840.

Embil J, Warren P, Yakrus M, et al. Pulmonary illness associated with exposure to Mycobacterium-avium complex in hot tub water. Hypersensitivity pneumonitis or infection? Chest 1997; 111: 813-816.

Kahana LM, Kay JM, Yakrus MA, et al. Mycobacterium avium complex infection in an immunocompetent young adult related to hot tub exposure. Chest 1997; 111: 242-245.

Tillie-Leblond I, Grenouillet F, Reboux G, et al. Hypersensitivity pneumonitis and metalworking fluids contaminated by mycobacteria. Eur Respir J 2011; 37: 640-647. 
Flight WG, Bright-Thomas RJ, Tilston P, et al. Incidence and clinical impact of respiratory viruses in adults with cystic fibrosis. Thorax 2014; 69: 247-253.

van Ewijk BE, van der Zalm MM, Wolfs TF, et al. Prevalence and impact of respiratory viral infections in young children with cystic fibrosis: prospective cohort study. Pediatrics 2008; 122: 1171-1176.

Wat D, Gelder C, Hibbitts S, et al. The role of respiratory viruses in cystic fibrosis. J Cyst Fibros 2008; 7: $320-328$.

de Almeida MB, Zerbinati RM, Tateno AF, et al. Rhinovirus $\mathrm{C}$ and respiratory exacerbations in children with cystic fibrosis. Emerg Infect Dis 2010; 16: 996-999.

Flight WG, Bright-Thomas RJ, Sarran C, et al. The effect of the weather on pulmonary exacerbations and viral infections among adults with cystic fibrosis. Int J Biometeorol 2014; 58: 1845-1851.

Ramirez IA, Caverly LL, Kalikin LM, et al. Differential responses to rhinovirus- and influenza-associated pulmonary exacerbations in patients with cystic fibrosis. Ann Am Thorac Soc 2014; 11: 554-561.

Collinson J, Nicholson KG, Cancio E, et al. Effects of upper respiratory tract infections in patients with cystic fibrosis. Thorax 1996; 51: 1115-1122.

Wang EE, Prober CG, Manson B, et al. Association of respiratory viral infections with pulmonary deterioration in patients with cystic fibrosis. N Engl J Med 1984; 311: 1653-1658.

Smyth AR, Smyth RL, Tong CY, et al. Effect of respiratory virus infections including rhinovirus on clinical status in cystic fibrosis. Arch Dis Child 1995; 73: 117-120. aeruginosa in patients with cystic fibrosis in Denmark. Thorax 1992; 47: 109-111.

van Ewijk BE, Wolfs TF, Fleer A, et al. High Pseudomonas aeruginosa acquisition rate in CF. Thorax 2006; 61: 641-642.

Van Ewijk BE, Wolfs TF, Aerts PC, et al. RSV mediates Pseudomonas aeruginosa binding to cystic fibrosis and normal epithelial cells. Pediatr Res 2007; 61: 398-403.

Holt PG, Strickland DH, Sly PD. Virus infection and allergy in the development of asthma: what is the connection? Curr Opin Allergy Clin Immunol 2012; 12: 151-157.

Sorkness RL, Szakaly RJ, Rosenthal LA, et al. Viral bronchiolitis in young rats causes small airway lesions that correlate with reduced lung function. Am J Respir Cell Mol Biol 2013; 49: 808-813.

Poorisrisak P, Halkjaer LB, Thomsen SF, et al. Causal direction between respiratory syncytial virus bronchiolitis and asthma studied in monozygotic twins. Chest 2010; 138: 338-344.

rreymuth F, Vabret A, Dina J, et al. Les virus des bronchiolites aigues [Bronchiolitis viruses]. Arch Pediatr 2010; 17: 1192-1201.

Jackson DJ, Gangnon RE, Evans MD, et al. Wheezing rhinovirus illnesses in early life predict asthma development in high-risk children. Am J Respir Crit Care Med 2008; 178: 667-672.

Lee WM, Lemanske RF Jr, Evans MD, et al. Human rhinovirus species and season of infection determine illness severity. Am J Respir Crit Care Med 2012; 186: 886-891.

Palmenberg AC, Rathe JA, Liggett SB. Analysis of the complete genome sequences of human rhinovirus. J Allergy Clin Immunol 2010; 125: 1190-1199.

Carroll KN, Gebretsadik T, Minton P, et al. Influence of maternal asthma on the cause and severity of infant acute respiratory tract infections. J Allergy Clin Immunol 2012; 129: 1236-1242.

Sigurs N, Aljassim F, Kjellman B, et al. Asthma and allergy patterns over 18 years after severe RSV bronchiolitis in the first year of life. Thorax 2010; 65: 1045-1052.

Bacharier LB, Cohen R, Schweiger T, et al. Determinants of asthma after severe respiratory syncytial virus bronchiolitis. J Allergy Clin Immunol 2012; 130: 91-100.

Stein RT, Sherrill D, Morgan WJ, et al. Respiratory syncytial virus in early life and risk of wheeze and allergy by age 13 years. Lancet 1999; 354: 541-545.

James KM, Gebretsadik T, Escobar GJ, et al. Risk of childhood asthma following infant bronchiolitis during the respiratory syncytial virus season. J Allergy Clin Immunol 2013; 132: 227-229.

Kotaniemi-Syrjanen A, Vainionpaa R, Reijonen TM, et al. Rhinovirus-induced wheezing in infancy - the first sign of childhood asthma? J Allergy Clin Immunol 2003; 111: 66-71.

Valkonen H, Waris M, Ruohola A, et al. Recurrent wheezing after respiratory syncytial virus or non-respiratory syncytial virus bronchiolitis in infancy: a 3-year follow-up. Allergy 2009; 64: 1359-1365.

Midulla F, Pierangeli A, Cangiano G, et al. Rhinovirus bronchiolitis and recurrent wheezing: 1-year follow-up. Eur Respir J 2012; 39: 396-402.

Kusel MM, de Klerk NH, Kebadze T, et al. Early-life respiratory viral infections, atopic sensitization, and risk of subsequent development of persistent asthma. J Allergy Clin Immunol 2007; 119: 1105-1110.

Lemanske RF Jr, Jackson DJ, Gangnon RE, et al. Rhinovirus illnesses during infancy predict subsequent childhood wheezing. J Allergy Clin Immunol 2005; 116: 571-577.

Guilbert TW, Singh AM, Danov Z, et al. Decreased lung function after preschool wheezing rhinovirus illnesses in children at risk to develop asthma. J Allergy Clin Immunol 2011; 128: 532-538.

Caliskan M, Bochkov YA, Kreiner-Moller E, et al. Rhinovirus wheezing illness and genetic risk of childhood-onset asthma. N Engl J Med 2013; 368: 1398-1407.

1 Raedler D, Illi S, Pinto LA, et al. IL10 polymorphisms influence neonatal immune responses, atopic dermatitis, and wheeze at age 3 years. J Allergy Clin Immunol 2013; 131: 789-796.

Jartti T, Kuusipalo H, Vuorinen T, et al. Allergic sensitization is associated with rhinovirus-, but not other virus-, induced wheezing in children. Pediatr Allergy Immunol 2010; 21: 1008-1014.

3 Jackson DJ, Evans MD, Gangnon RE, et al. Evidence for a causal relationship between allergic sensitization and rhinovirus wheezing in early life. Am J Respir Crit Care Med 2012; 185: 281-285.

4 Stern DA, Guerra S, Halonen M, et al. Low IFN-gamma production in the first year of life as a predictor of wheeze during childhood. J Allergy Clin Immunol 2007; 120: 835-841.

Sumino K, Tucker J, Shahab M, et al. Antiviral IFN-gamma responses of monocytes at birth predict respiratory tract illness in the first year of life. J Allergy Clin Immunol 2012; 129: 1267-1273.

6 Jackson DJ, Sykes A, Mallia P, et al. Asthma exacerbations: origin, effect, and prevention. J Allergy Clin Immunol 2011; 128: 1165-1174. 
157 van der Zalm MM, Uiterwaal CS, Wilbrink B, et al. The influence of neonatal lung function on rhinovirus-associated wheeze. Am J Respir Crit Care Med 2011; 183: 262-267.

158 Chawes BL, Poorisrisak P, Johnston SL, et al. Neonatal bronchial hyperresponsiveness precedes acute severe viral bronchiolitis in infants. J Allergy Clin Immunol 2012; 130: 354-361.

159 Pernet E, Guillemot L, Burgel PR, et al. Pseudomonas aeruginosa eradicates Staphylococcus aureus by manipulating the host immunity. Nat Commun 2014; 5: 5105.

160 Cui L, Morris A, Huang L, et al. The microbiome and the lung. Ann Am Thorac Soc 2014; 11: Suppl. 4, S227-S232.

161 Choi IS, Koh YI. Therapeutic effects of BCG vaccination in adult asthmatic patients: a randomized, controlled trial. Ann Allergy Asthma Immunol 2002; 88: 584-591. 